\title{
Analysis Of Communication Process In Counseling Through Whatsapp
}

\author{
Evia Darmawani ${ }^{1}$, Ahmad Rofi Suryahadikusumah ${ }^{2}$ \\ ${ }^{12}$ Program Studi Bimbingan dan Konseling, Universitas PGRI Palembang \\ Correspondence:ahmadrofi@univpgri-palembang.ac.id
}

\begin{abstract}
Abstrak: Penelitian ini bertujuan untuk menganalisis proses komunikasi konseling yang merujuk kepada dimensi komunikasi efektif dalam konseling. pendekatan mix method digunakan dengan one phase design. Penelitian dilakukan kepada 25 responden yang merupakan siswa SMK PGRI 2 Palembang yang memanfaatkan konseling melalui WhatsApp di sekolah tersebut. Metode kuantitatif digunaka untuk mensurvey ketercapaian aspek komunikasi dalam konseling melalui WhatsApp, sedangkan metode kualitatif digunakan untuk mendalami pola komunikasi yang terjadi. Hasil penelitian menunjukkan bahwa aspek rasa nyaman dan keterbukaan merupakan pengalaman yang paling dirasakan responden, sedangkan $50 \%$ responden mengakui kurang merasakan dimensi empati. Penelitian merekomendasikan untuk1) tetap menggunakan prinsip dalam konseling dalam konseling melalui WhatsApp, terutama dalam pembentukan rapport,2) memahami penggunaan kata - kata , emoticon, dan gaya bahasa dalam komunikasi digital, 3) mengggunakan pendekatan naratif dan solution focused ketika melakukan konseling melalui WhatsApp.
\end{abstract}

Kata kunci: komunikasi konseling, WhatsApp

\begin{abstract}
The research aim to analyze counseling communication processes that discuss the dimensions of effective communication in counseling. The mixed method is used with a one-phase design. The study was conducted on 25 respondents who were students of SMK PGRI 2 Palembang who use counseling through WhatsApp at their school. Quantitative methods used for surveying aspects of communication in counseling through WhatsApp, while qualitative methods are used to explore patterns of communication that occur. The results showed that the aspects of comfort and openness were the most considered experiences of respondents, while $50 \%$ of respondents considered lacking the empathy dimension. Research recomendating to 1) use principles in counseling in WhatsApp counseling, especially in rapport relations, 2) mastering the use of words, emoticons, and language styles in digital communication, 3) use narrative approaches and solutions focused on compiling counseling through WhatsApp.
\end{abstract}

Keyword: communication counseling, whatsapp

\section{PENDAHULUAN}

Pengembangan teknologi dan informasi dalam layanan bimbingan dan konseling bertujuan untuk mempermudah penyampaian layanan. Salah satu aspek yang menjadi perhatian penting adalah komunikasi. Perubahan kebiasaan dan cara berkomunikasi yang dilakukan siswa menjadi dasar berkembangnya berbagai media dan teknologi dalam bimbingan, agar relevan, menarik, dan dapat diakses dengan baik.

Di era millenials, terjadi pergeseran cara berkomunikasi yang berawal dari face to face, menjadi inter face melalui perangkat online. Fakta ditemukan dalam Roy Morgan (Zein, 2019) sembilan dari sepuluh anak dan remaja $(89 \%)$ berkomunikasi secara online dengan 
teman-teman, sementara kelompok-kelompok yang lebih kecil juga berinteraksi dengan keluarga mereka (56\%) atau guru mereka (35\%) melalui internet. Sejalan dengan temuan tersebut, Kementrian komunikasi dan informasi bersama Unicef (2014) menjelaskan dalam studinya bahwa 30 juta remaja di Indonesia merupakan pengguna internet, dan media digital menjadi pilihan dalam berkomunikasi.

Internet mengambil peran dalam merubah kebiasaan berkomunikasi di setiap lini kehidupan peserta didik termasuk dalam interaksi dan komunikasi dengan guru BK. Kaplan (Suryahadikusumah \& Ferdiansyah, 2018) berpendapat bahwa konselor dapat menjaga kualitas layanan di era digital dengan pemanfaatan dan pengembangan sosial media.

Penggunaan WhatsApp sebagai media konseling mulai banyak dikembangkan oleh guru BK di sekolah. Penggunaan WhatsApp sebagai media komunikasi sehari merupakan faktor utama yang mendorong guru BK untuk menjadikannya sebagai media layanan konseling kepada siswa.

Contohnya saja, Mbayu \& Budianto (2019) melakukan penerapan WhatsApp dengan menggunakan metode Forward Chaining berbasis smart phone yang menyediakan berbagai solusi untuk memecahkan beberapa persoalan siswasiswi dalam bimbingan konseling. selain itu, temuan Budianto et. al. (2019) menunjukkan dengan mengoptimalkan WhatsApp berdasarkan komputasi mobile, para peneliti telah dapat membantu para guru dalam memecahkan masalah konseling siswa dengan akurasi $80 \%$.

Konseling melalui WhatsApp secara teoritis termasuk pada kategori cybercounseling chat-asynchonous, artinya konselor tidak dituntut untuk menanggapi langsung pesan yang dikrimkan oleh konseli. Prasetya (2017) menjelaskan, dalam suasana konseling konselor mempunyai waktu untuk berpikir, mengevaluasi, dan menulis balasan untuk konseli tersebut.

Dari banyaknya penelitian mengenai konseling menggunakan WhatsApp selalu berfokus kepada pengembangan model dan efektifitasnya, sementara kajian terhadap proses konselingnya belum tersentuh oleh sebuah riset. Di lain pihak, banyak yang masih meragukan kebenaran proses komunikasi yang terjadi dalam
WhatsApp merupakan proses komunikasi konseling atau bukan.

Perbedaan proses komunikasi konseling secara tatap muka dengan melalui whatapp tentunya akan berpengaruh kepada efisiensi dan efektifitas proses konseling. Hakikatnya konseling merupakan proses komunikasi, dan komunikasi adalah jantungnya konseling.

Baik buruknya, dan lancar tidaknya proses komunikasi akan berdampak pada proses konseling yang terjadi. Terciptanya komunikasi guru bimbingan dan konseling dengan siswa yang berkualitas dan sesuai dengan harapan siswa merupakan landasan, dan akan memberikan pengaruh positif bagi terselenggaranya layanan konseling (Suherman, 2019). Selain itu, komunikasi dalam konseling memiliki ciri khas yang disebut helping relationship.

Berdasarkan perbandingan antara hasil penelitan terdahulu dengan fakta yang ada, maka peneliti merasa pelu untuk mengkaji proses komnuikasi yang terjadi dalam konseling melalui WhatsApp. Tujuan dari kajian ini adalah untuk mendalami nilai efektifitas pelaksanaan konseling melalui whatasapp jika ditinjau dari sisi proses komunikasi yang terjadi, dan merujuk kepada dimensi komunikasi efektif dalam konseling. Sehingga keyakinan akan penggunaan WhatsApp sebagai media layanan konseling dapat tervalidasi dengan komperhensif.

\section{METODE}

Penelitian dilakukan dengan pendekatan mix method one phase design, dengan metode triangulasi. Metode penlitian triangulasi adalah mengumpulkan data kuantitatif dan kualitatif secara bersamaan, menggabungkan data, dan menggunakan hasilnya untuk memahami masalah penelitian (Sheperis, Young, Daniels, 2010). Oleh karena itu metode ini dipilih agar dapat melakukan analisis seacara mendalam, seperti yang digambarkan pada gambar 1 .

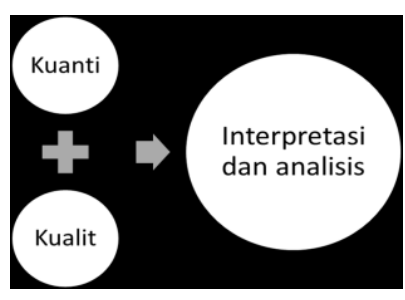

Gambar 1. Penelitian Desain Triangulasi 
Metode kuantitatif dilakukan dengan cara melakukan survey menggunakan angket kepada 25 responden yang telah memanfaatkan konseling melalui WhatsApp. Metode kualitatif dilakukan dengan mengajukan pertanyaan terbuka berupa alasan siswa memanfaatkan konseling melalui WhatsApp, serta kekutan dan keterbatasan komunikasi yang dirasakan selama melakukan konseling melalui WhatsApp.

Penelitian dilakukan di SMK PGRI 2 Palembang. Pemilihan sampel dilakukan secara purposif, yaitu memilih siswa yang tercatat sering melakukan sesi konseling melalui WhatsApp, diperoleh sebanyak 20 orang.

Aspek yang dikaji dalam penelitian diambil dari dimensi komunikasi efektif dalam konseling. Secara rinci aspek tersebut antara lain
1) menimbulkan rasa senang \& nyaman, 2) adanya keterbukaan, 3) empati dalam proses penyelesaian.

\section{HASIL DAN PEMBAHASAN}

Analisis pertama dalam penelitian ialah menemukan deskripsi ketercapaian setiap aspek pada dimensi komunikasi efektif ketika siswa melakukan konseling melalui WhatsApp. Ketercapaian setiap aspek dikonversi dalam bentuk persentase, kemudian dikelompokkan pada tiga kategori yaitu kurang, cukup, dan maksimal. Hasil temuan pertama disajikan pada tabel 1 dibawah ini.

Tabel.1 Ketercapaian setiap aspek dimensi komunikasi efektif.

\begin{tabular}{llcc}
\hline \multicolumn{1}{c}{ Aspek } & Kategori & F & \% \\
\hline \multirow{2}{*}{$\begin{array}{l}\text { Menimbulkan rasa senang \& } \\
\text { nyaman }\end{array}$} & Kurang & 2 & 10 \\
& Cukup & 6 & 30 \\
& Maksimal & 12 & 60 \\
\multirow{2}{*}{ Adanya Keterbukaan } & Kurang & 3 & 15 \\
& Cukup & 9 & 45 \\
\multirow{2}{*}{$\begin{array}{l}\text { Empati dalam proses } \\
\text { penyelesaian }\end{array}$} & Maksimal & 8 & 40 \\
& & & 50 \\
& Kurang & 10 & 25 \\
& Cukup & 5 & 2
\end{tabular}

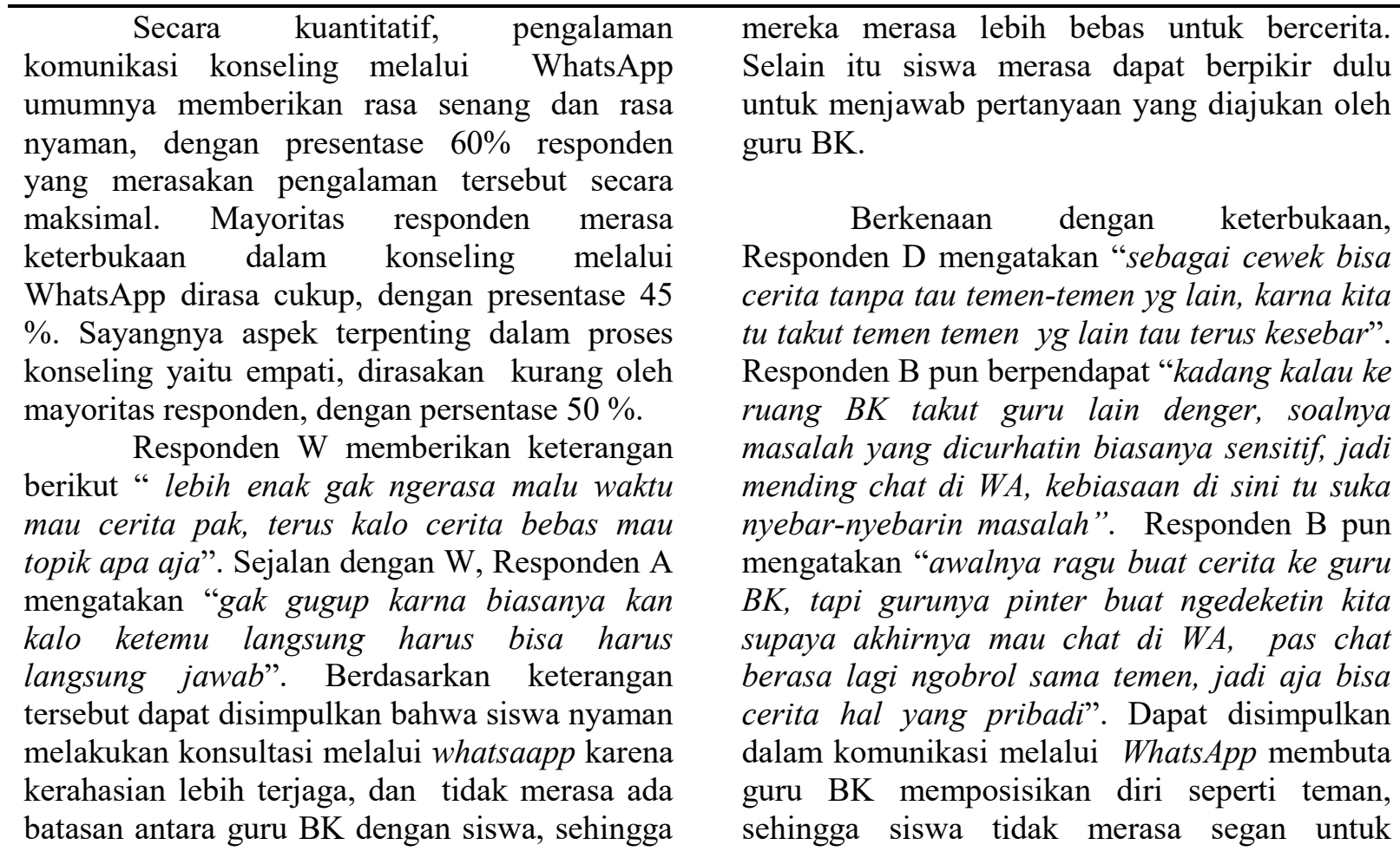


bercerita, selain itu faktor kerahasiaan kembali menjadi penentu siswa untuk membuka diri kepada guru BK.

Aspek empati yang dirasakan oleh siswa menurut W adalah " kadang gurunya suka pake emoji , sama bahasanya pake bahasa sehari hari, jadinya kerasa santai juga kalau cerita dan ngerasa ditanggepin sama temen". Namun kelemahan yang dirasakan oleh siswa adalah respon yang terkadang lama mereka peroleh, seperti yang diungkapkan oleh D "guru suka bales chatnya lama pak, padahal kita suka pengen cepet tau balesannya apa, dan kita harus ngapain". Berdasarkan keterangan tersebut harapan siswa ketika mereka melakukan konseling melalui WhatsApp bukan hanya kenyamanan, namun juga kecepatan dan ketetapan respon dari guru BK, siswa pun menganggap dengan chat melalui WhatsApp mereka akan lebih cepat mendapatkan solusi.

Dengan demikian, secara kualitatif gambaran pengalaman komunikasi konseling melalui WhatsApp dapat disimpulkan dalam bentuk tabel perbandingan, yang disajikan dalam tabel 2 di bawah ini.

Tabel 2. Gambaran Proses Komunikasi Konseling Melalui WhatsApp

\begin{tabular}{clcl}
\hline Aspek & \multicolumn{2}{c}{ Guru BK } & \multicolumn{2}{c}{ Siswa } \\
\hline & Tidak memberikan batasan & Tidak gugup karena \\
& masalah yang dapat dibahas memiliki waktu untuk \\
& melalui & WhatsApp, memikirkan jawaban/ \\
Menimbulkan rasa senang \& nyaman & memberikan waktu yang & $\begin{array}{l}\text { respon pada guru BK, } \\
\text { fleksibel untuk merespon merasa malu untuk }\end{array}$ \\
& & tidak mercerita
\end{tabular}

Melakukan pendekatan Merasakan keamanan personal kepada siswa, akan rahasia masalah

Adanya Keterbukaan

Empati dalam proses penyelesaian memberikan jaminan yang disampaikan, dapat kerahasiaan menceritakan masalah yang sensitif sekalipun

Menggunakan emoji sebagai Merasa berkomunikasi ekspresi perasaan, dengan temannya, namun menggunakan bahasa sehari - tetap mengharapkan hari, memposisikan diri respon cepat dari guru seperti teman BK
Secara umum, keunggulan komunikasi konseling melalui WhatsApp adalah kemudahan konseli / siswa untuk membuka diri kepada guru BK. Surya (2009) membuka diri merupahakan hal yang penting dalam mewujudkan komunikasi antarpribadi secara efektif. Membuka diri merupakan tindakan dengan menunjukan diri sendiri sehingga membuat orang lain mengenal diri kita. keterbukaan diri dalam konseling yaitu mengungkapkan reaksi atau tanggapan kita terhadap situasi yang sedang kita hadapi serta memberikan informasi tentang masa lalu yang relevan untuk memahami tanggapan kita dimasa kini. Komunikasi dalam konseling akan berjalan lancar jika konseli mau membagikan perasaannya terhadap suatu yang telah dikatakan atau dilakukan, atau kejadian yang baru saja dialami.
Temuan dalam penelitian sejalan dengan hasil penelitian Teh, Acosta, Hechanova, Garabiles (2014) yang menyatakan responden memang memiliki sikap positif terhadap konseling online dan keterbukaan untuk mencobanya walaupun tidak harus bermaksud untuk mengganti konseling tatap muka. Selain faktor kerahasiaan, penggunaan bahasa dan kata kata dalam bentuk teks menjadi faktor penentu keberhasilan konseling melalui WhatsApp. Seperti yang diungkapkan Kraus, R., Stricker, G., \& Speyer, C. ( Petrus \& Sudibyo, 2017) bahwa ikatan berbasis teks, dan dengan kehadiran dirasakan terapis, konseli dapat mengalami kebebasan ekspresi diri dan pertumbuhan kesadaran diri yang sangat berarti dari dialog online.

Kemampuan guru BK menggunakan bahasa, basis komunikasi teks secara online 
menjadi konteks empati dalam komunikasi konseling melalui WhatsApp. Secara konseptual, Surya (2009) menjelaskan empati sebagai bentuk kesediaan untuk memahami orang lain dalam aspek perasaan, dan pikiran, serta dapat menempatkan diri dalam suasana perasaan sehingga dapat menghayati bagaimana perasaan kita apabila dalam situasi orang lain. Berdasarkan analisis kualitatif, bentuk empati yang dilakukan dalam konseling melalui WhatsApp adalah penggunaan emoji sebagai ekspresi perasaan dan cara guru BK memposisikan diri sebagai teman curhat, sehingga menggunakan bahasa sehari - hari yang membuat siswa merasa dekat.

Persoalan empati masih perlu diperhatikan dalm komunikasi konseling melalui WhatsApp, pasalnya berdasarkan penelitian aspek empati masih dirasa kurang oleh responden yaitu sekitar 50\%. responden. Guru BK perlu memahami kecenderungan siswa menggunakan konseling secara online biasanya didasari oleh masalah yang dirasakan mendesak (krisis), sehingga siswa menuntut respon cepat.

Oleh karena itu jika kembali pada basis proses konseling, dalam konseling melalui WhatsApp tetap harus dilakukan rapport. Teknik rapport merupakan bentuk empati yang dimunculkan oleh konselor untuk memberikan kesan baik diawal sehingga mendapatkan penerimaan dari konseli. Berbeda dengan rapprot dalam konseling tatap muka yang menekankan pada kenyamanan secara fisik (tampilan, sapaan, posisi duduk, dan lain sebagainya), dalam konseling online rapport ditekankan pada persetujuan kemungkinan jalannya sebuah konseling dalam chat room.

Dalam komunikasi online, istilah "netiket" digunakan sebagai tata krama, sopan santun, dan aturan main yang harus diperhatikan agar hubungan yang dibentuk oleh kedua user berjalan dengan baik. Sehubungan dengan hal tersebut, Nagel \& Anthony (2011) menjelaskan penggunaan konvensi berbasis teks di Internet, atau "netiket," dapat membantu memfasilitasi hubungan dalam sesi terapi obrolan. Contoh dari netiket adalah konselor menginformasikan jika membutuhkan durasi waktu tertentu untuk membalas pesan (chat), memberikan dukungan (support) dengan menggunakan emoji, serta memberikan isyarat yang mudah dipahami oleh konseli (biasanya dengan istilah - istilah yang sedang trend saat ini).

Degan demikian pada dasarnya prinsip pengalaman komunikasi yang dibangun dalam konseling melalui WhatsApp dengan tatap muka tidak jauh berbeda secara konseptual. Prinsip prinsip dalam konseling tatap muka tetap digunakan dalam konseling melalui WhatsApp karena pada dasarnya sama sama professional helping relationship (hubungan membantu yang profesional). Perbedaannya hanyalah pada konteks perilaku, dalam konseling melalui WhatsApp konteks keterbukaan, kenyamanan, dan empati diwujudkan dalam narasi tekstual dan simbol - simbol emosi (emoticon).

Dalam konseling melalui WhatsApp guru BK tetap harus melakukan rapport, asesmen, penetapan tujuan, pemeliharaan hubungan, dan melakukan tindak lanjut. Beberapa kompetensi yang diperlukan agar proses komunikasi konseling melalui WhatsApp berjalan dengan efektif dan profesional antara lain sebagai berikut: (1) Pemahaman terhadap fitur dalam aplikasi chat, dan maknanya (seperti penggunaan emoticon, gif, pesan suara, dll.); (2) Penggunaan variasi bahasa dan kalimat seperti penggunaan istilah, akronim, dan padanan kata. Misalkan saja untuk remaja mereka akan lebih suka dengan bahasa yang santai, kasual, dan menggunakan beberapa istilah atau singkatan; (3) Kemampuan untuk mengarahkan dan mengatur ritme obrolan, seperti mengajukan pertanyaan reflektif, membiarkan konseli bercerita dengan bebas, memberikan waktu untuk berpikir, atau merespon dengan cepat; (4) Memilih pendekatan dalam penyelesaian masalah. Terdapat dua pendekatan yang diyakini dapat membantuk konseling berbasis teks, yaitu naratif dan solution focused. Dalam pendekatan naratif guru BK dapat mengulang atau merangkum ulang cerita siswa selama chat kemudian memberikan intisari ide tindakan perubahan yang dapat dilakukan berdasarkan cerita tersebut, seangkan dalam pendekatan solution focused guru BK menggali perilaku solutif yang pernah dilakukan siswa sebelumnya yang mungkin akan bisa dilakukan untuk persoalan yang diobrolkan dalam chat.

\section{SIMPULAN DAN SARAN}

Hasil analsis proses komunikasi konseling melalui WhatsApp menunjukkan, empati sebagai aspek komunikasi yang belum maksimal. Secara kuantitatif ditemukan 50\% responden merasa kurang merasakan empati ketika melakukan konseling melalui WhatsApp. Siswa memiliki ekspektasi untuk mendapat respon cepat, namun disamping itu mereka 
memerlukan juga waktu untuk menjawab pertanyaan guru BK.

Oleh karena itu direkomendasikan dalam melakukan konseling melalui WhatsApp tetap menggunakan prinsip dalam konseling tatap muka, terutama dalam pembentukan rapport, yang dalam konteks komunikasi digital disebut netiket agar siswa dapat memahami dan menerima proses konseling yang akan dilakukan. Selain itu, guru BK perlu menguatkan kompetensi dalam berkomunikasi digital dan menggunakan pendekatan konseling berupa pendekatan naratif dan solution focused, agar proses komunikasi konseling melalui WhatsApp lebih efektif dan profesional.

\section{DAFTAR RUJUKAN}

Budianto, A. E., Aziz, A., \& Hidayah, N. (2019). ICT application in cyber counseling as a teacher accelerator with optimizing WhatsApp based mobile computing. In Journal of Physics: Conference Series (Vol. 1375, No. 1, p. 012006). IOP Publishing.

Mbayu, S. H., \& Budianto, A. E. (2019). Penerapan WhatsApp Sebagai Media Bimbingan Konseling Metode Forward Chainng Berbasis Smartphone. Semnas SENASTEK Unikama 2019, 2.

Nagel, D. M., \& Anthony, K. (2011). Textbased online counseling: Chat. In Online Counseling (pp. 169-182). Academic Press.

Petrus, J., \& Sudibyo, H. (2017). Kajian Konseptual Layanan Cyberconseling. Konselor, 6(1), 6-12.

Prasetya, A. F. (2017). Model Cybercounseling: Telaah Konseling Individu Online ChatAsynchronous Berbasis Aplikasi Android. In Prosiding Seminar Bimbingan dan Konseling (Vol. 1, No. 1, pp. 31-38).

Sheperis, CJ, Young, JS, \& Daniels, MH (2010). Counseling research: Quantitative, qualitative, and mixed methods. Upper Saddle River, NJ: Pearson Education

Suherman, S. (2019). Dimensi-dimensi Komunikasi Efektif dalam Relasi Bimbingan dan Konseling. Indonesian Journal of Educational Counseling, 3(3), 169-178.

Surya, M. (2009). Psikologi Konseling. Bandung : Maestro

Suryahadikusumah, A. R., \& Ferdiansyah, M.
(2018). The Use Of Social Media In Guidance And Counseling Service Through Project Based Learning Activity (An Action Research With Guidance And Counseling Students of Universitas PGRI Palembang). Jurnal Dosen Universitas PGRI Palembang.

Teh, L. A., Acosta, A. C., Hechanova, M. R. M., Garabiles, M. R., \& Alianan Jr, A. S. (2014). Attitudes of psychology graduate students toward face-to-face and online counseling. Philippine Journal of Psychology, 47(2), 1-1.

Zein, M. F. (2019). Anak dan Keluarga dalam Teknologi Informasi. Tersedia di : https://books.google.co.id/books 